\title{
Features of the metabolic syndrome and the risk of non-vertebral fractures: The Tromso Study
}

\author{
Luai A. Ahmed • Henrik Schirmer • Gro K. Berntsen • \\ Vinjar Fønnebø • Ragnar M. Joakimsen
}

Published online: 31 January 2009

(C) International Osteoporosis Foundation and National Osteoporosis Foundation 2009

\section{Erratum to: Osteoporos Int (2006) 17: 426-432 \\ DOI 10.1007/s00198-005-0003-z}

Owing to a technical error, a number of non-vertebral fractures had not been included in the database.

Owing to changes in the informed consents for some of the participants, at the time of repeated analyses, the study cohort changed from 27,159 to 26,905 participants. A total of 1,882 non-vertebral fractures (not 1,249 as stated in the publication) were registered.

After excluding all subjects with missed measurements of any metabolic syndrome criteria $(n=152), 750$ men and 1108 women (not 438 men and 789 women as stated in the publication) suffered non-vertebral fractures.

The risk estimates of the associations between having three or more of the metabolic syndrome criteria and nonvertebral fractures and changed to (RR $0.81,95 \%$ CI 0.64 1.04 ) in men and (RR 0.78, 95\% CI 0.65-0.93) in women. The trend towards reduced fracture risk by increasing mean $\mathrm{BP}$ in men was no longer significant (Fig. 2).

We apologize for any inconvenience caused by this unfortunate error.

The online version of the original article can be found at http://dx.doi. org/10.1007/s00198-005-0003-z

L. A. Ahmed $(\bowtie) \cdot H$. Schirmer · G. K. Berntsen · V. Fønnebø Institute of Community Medicine, University of Tromsø,

9037 Tromsø, Norway

e-mail: Luai.Awad@ism.uit.no

H. Schirmer

Department of Cardiology, University Hospital of Tromsø,

Tromsø, Norway

R. M. Joakimsen

Department of Internal Medicine, University Hospital of Tromsø,

Tromsø, Norway 